\title{
Oral consumption of a-linolenic acid increases serum BDNF levels in healthy adult humans
}

\author{
Mahmoudreza Hadjighassem ${ }^{1,5^{*}}$, Behnam Kamalidehghan ${ }^{2}$, Nima Shekarriz ${ }^{3}$, Argavan Baseerat ${ }^{3}$, Nima Molavi ${ }^{3}$, \\ Masoud Mehrpour ${ }^{4}$, Mohammad Taghi Joghataei ${ }^{1,6}$, Mahdi Tondar $^{7}$, Fatemeh Ahmadipour ${ }^{2}$ and Goh Yong Meng ${ }^{8}$
}

\begin{abstract}
Background aims: Dietary omega- 6 and omega-3 fatty acids have remarkable impacts on the levels of DHA in the brain and retina. Low levels of DHA in plasma and blood hamper visual and neural development in children and cause dementia and cognitive decline in adults. The level of brain-derived neurotrophic factors (BDNF) changes with dietary omega-3 fatty acid intake. BDNF is known for its effects on promoting neurogenesis and neuronal survival.
\end{abstract}

Methods: In this study, we examined the effect of the oral consumption of a-Linolenic acid (ALA) on blood levels of BDNF and Malondialdehyde (MDA) in healthy adult humans. 30 healthy volunteers, 15 men and 15 women, were selected randomly. Each individual served as his or her own control. Before consuming the Flaxseed oil capsules, $5 \mathrm{cc}$ blood from each individual was sampled in order to measure the plasma levels of BDNF and MDA as baseline controls. During the experiment, each individual was given 3 oral capsules of flaxseed oil, containing 500mg of alpha linolenic acid, daily for one week. Then, plasma levels of BDNF and MDA were tested.

Results: The plasma levels of BDNF and MDA significantly $(P<0.05)$ increased in individuals who received the oral capsules of ALA. Plasma levels of BDNF increased more in the women in comparison with the men.

Conclusion: ALA treatment could be a feasible approach to reduce size of infarcts in stroke patients. Thus, ALA could be used in adjunction with routine stroke therapies to minimize brain lesions caused by stroke.

Keywords: a-Linolenic acid, Oral consumption, BDNF level, Neuroprotective effects, Stroke

\section{Introduction}

The long chain omega- 3 fatty acid with 6 double bonds and 22 carbons, docosahexaenoic acid (DHA), is the most abundant omega-3 fatty acid in the mammalian central nervous system. DHA is concentrated in the visual units of retina and membrane lipids of the brain grey matter. Levels of DHA increase during mammalian development and reduce by aging [1-5].

Many researchers have shown that dietary $\omega-6$ and omega $\omega-3$ fatty acids have remarkable impact on the levels of DHA in brain and retina [6,7]. Furthermore, according to many epidemiological studies, low levels of DHA in plasma and blood hamper visual and neural

\footnotetext{
* Correspondence: mhadjighassem@tums.ac.ir

${ }^{1}$ Cellular and Molecular Research Center, Iran University of Medical Sciences,

Tehran, Iran

${ }^{5}$ Brain and Spinal Cord Research Center, School of Advanced Medical

Technologies, Tehran University of Medical Sciences, Tehran, Iran

Full list of author information is available at the end of the article
}

development in children and cause dementia and cognitive decline in adults [8-22].

A growing body of evidence indicates that omega-3 fatty acids have neuroprotective impact on the nervous system. These fatty acids influence the levels of neurotrophins, molecules that increase neuronal growth and survival. Among neurotrophins, the level of brain-derived neurotrophic factor (BDNF) changes with dietary omega3 fatty acids intake $[23,24]$. BDNF is known for its effects on promoting neurogenesis and neuronal survival $[25,26]$.

The $\alpha$-Linolenic acid (ALA; $18: 3 n-3)$ is a polyunsaturated omega- 3 fatty acid that has several neuroprotective effects [27-32]. In this study, we measured the plasma levels of BDNF and MDA in two groups of healthy participants, those who received ALA and those who did not. 
Table 1 Flax seed oil capsules

\begin{tabular}{lll}
\hline Flax seed oil & ALA & Company \\
\hline $1000 \mathrm{mg}$ & $530 \mathrm{mg}$ & Swissherbal \\
\hline
\end{tabular}

Each $1000 \mathrm{mg}$ flax seed oil capsule contained $530 \mathrm{mg}$ ALA.

\section{Material and methods}

This study was evaluated and approved by the Ethical Committee of the Tehran University of Medical Sciences. Thirty healthy volunteers, fifteen men and fifteen women, were selected randomly. They read and signed a consent form prior to enrolment in this study. These individuals had Body Mass Indexes (BMI) of less than thirty, similar low-fat diets, and no underlying diseases such as diabetes or high blood pressure. Because effective doses of ALA for increasing BDNF levels are unknown, each individual served as his or her own control.

Before consuming the Flaxseed oil [(Swiss, Canada) (Table 1)], 5cc blood from each individual was sampled in order to measure the plasma levels of BDNF and MDA as baseline controls. During the experiment, each individual was given 3 oral capsules of flaxseed oil, containing $500 \mathrm{mg}$ of ALA, daily for one week. Then, Plasma levels of BDNF and MDA were assessed using BDNF Emax ${ }^{\circ} \mathrm{Im}-$ munoAssay (Promega) and colorimetric Assay (Oxford Biomedical Research) kits according to the manufacturer's protocols, respectively.

\section{Statistical analysis}

GraphPad prism5 was applied to compare the levels of BDNF and MDA, after taking the capsules for one week, to their baselines. Numerical data are presented below as means \pm SEM. Statistical testing used Paired t-test analysis. Each test was performed at least two times and $\mathrm{P}<0.05$ was considered significant.

\section{Results}

This study revealed that plasma BDNF levels significantly $(\mathrm{P}<0.05)$ increased in individuals who received the oral

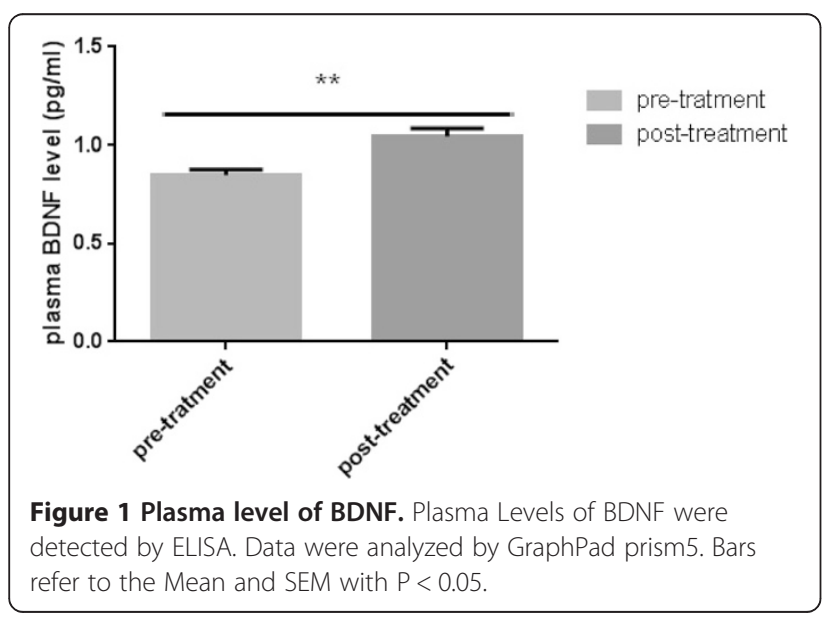

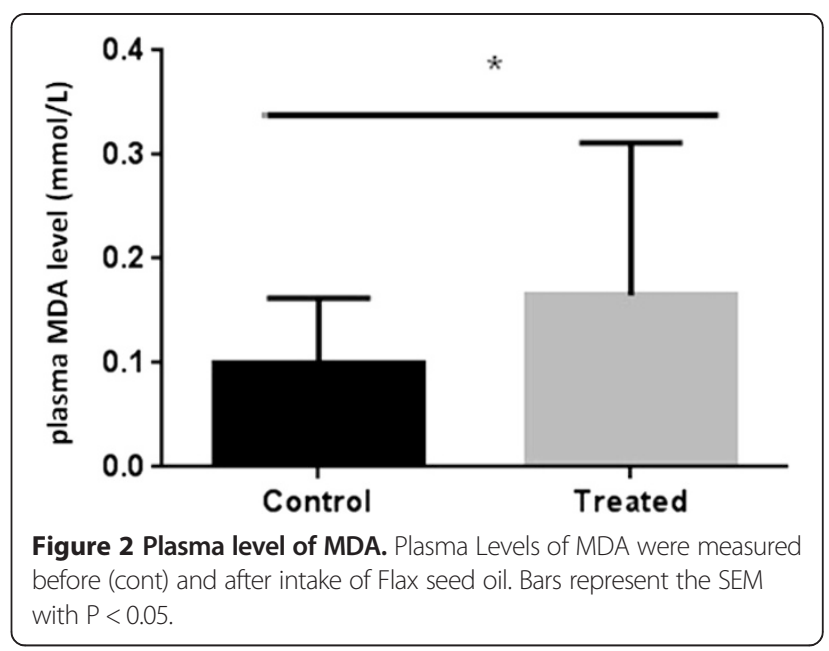

capsules of ALA (Figure 1). In order to determine whether or not this phenomenon was associated with peroxidation of fatty acids, plasma levels of MDA in the ALA group were measured, and they notably $(\mathrm{p}<0.05)$ increased. (Figure 2).

In addition, plasma levels of BDNF increased more in the women in comparison with the men. Although we observed a significant positive trend in increasing the BDNF levels in the men $(\mathrm{P}=0.01)$ (Table 2, Figure 3$)$.

\section{Discussion}

The neuroprotective roles of ALA have been reported in several stroke studies [27,31-36]. Recently, several molecular and clinical studies emphasized on the therapeutic potential of Omega-3 polyunsaturated fatty acids for treating a number of neurological and psychiatric diseases. Nevertheless, the mechanisms underlying these effects are still poorly understood.

In 2009, Blondeau et al. showed that subchronic ALA injections in mice induced neurogenesis in the hippocampus, increased in vivo and in vitro BDNF expression, promoted Neural Stem cell (NSCs) proliferation and synaptogenesis, enhanced synaptic vesicle fusion and protein levels, and induced antidepressant-like behavior. Furthermore, they observed that pre- and post-treatments with repeated ALA injections decreased the infarc volumes

Table 2 Data analysis of serum BDNF levels in males and females

\begin{tabular}{lllll}
\hline Sex & & Pretreatment & Post-treatment & P value \\
\hline Mean & Female & 0.7987 & 1.036 & 0.005 \\
Std.Deviation & & 0.1740 & 0.2035 & \\
Mean & Male & 0.8872 & 1.096 & 0.01 \\
Std.Deviation & 0.1270 & 0.1986 & \\
\hline
\end{tabular}




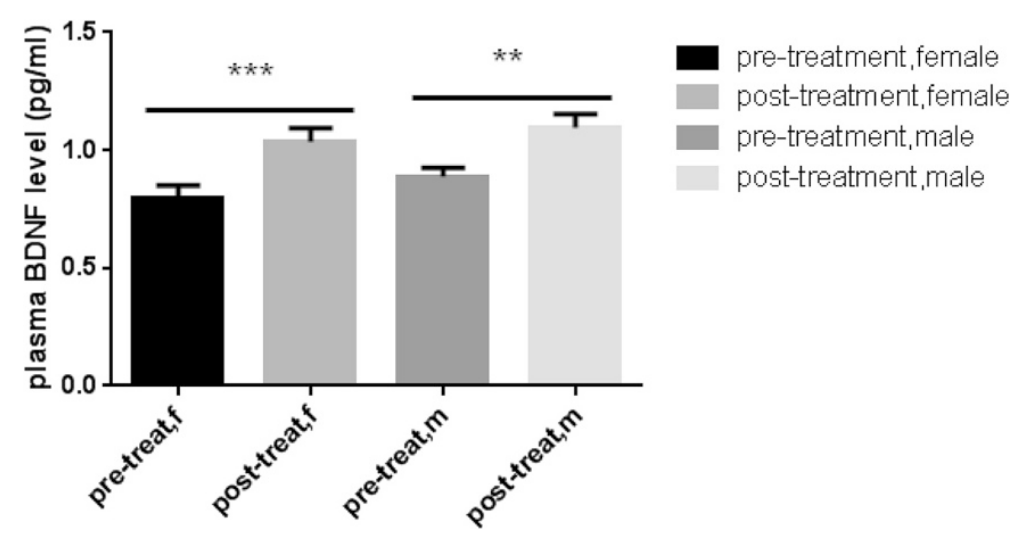

Figure 3 Sex dependency of BDNF change. BDNF levels were compared between the males and females before and after receiving the capsules.

and mortality caused by middle cerebral artery occlusion (MCAO) [37]. Nguemeni et al. in 2010 reported that dietary supplements of ALA in an enriched rapeseed oil diet could significantly reduce the MCAOinduced mortality rate and infarct volumes in mice [38]. In light of these studies on ALA, we examined the effect of dietary consumption of ALA on the blood levels of BDNF and MDA. To the best of our knowledge, this is the first study on healthy adult humans that measured both BDNF and MDA levels, used oral consumption of ALA, and determined sex differences in response to ALA intake. The results demonstrated that the levels of BDNF and MDA both increased in individuals who took ALA.

Neurotrophins are small proteins that are crucial for neuronal differentiation, growth, survival, and plasticity [39]. Nerve growth factor (NGF), brain-derived neurotrophic factor (BDNF), neurotrophin-3 (NT-3), and neurotrophin-4/5 (NT-4/5) are members of the mammalian neurotrophin family. The impact of these molecules on the nervous system is mediated by the tropomyosin receptor kinase (Trk) receptors and membrane-bound receptor tyrosine kinases that activate a number of cell signaling pathways which are linked to growth, differentiation, and survival [40]. The importance of neurotrophin signaling in brain development is well elucidated with findings that showed that knockout mice for any of the neurotrophins or their receptors were fatal or exhibited severe neural defects [41]. Neurotrophin signallings have important roles in the survival and integration of new neurons. For instance, BDNF triggers the TrkB receptor tyrosine kinases. BDNF also increases the number and survival of NSCs in the subventricular zone (SVZ) and olfactory bulbs $[42,43]$. Likewise, knocking down the TrkB receptors or disrupting the BDNF signaling pathway in dentate gyrus progenitors can lead to the formation of shorter dendrites, reduced spine, and eventually death [44].
BDNF signaling promotes the survival of newlygenerated neurons. In addition, defects in this pathway are associated with decreased neuronal survival and neurogenesis as well as the incidence and progression of several neurological disorders, such as schizophrenia, bipolar disorder, Alzheimer's disease, and age-related cognitive decline $[43,45,46]$. Furthermore, BDNF indirectly increases the transcription of $B c l-w$ gene, an antiapoptotic member of the Bcl-2 family [47]. Thus, BDNF decreases neuronal apoptosis. In addition, BDNF increases adhesion, migration, and survival of neurons. This neurotrophic molecule also enhances neurogenesis, synaptic plasticity, and neuronal differentiation through the BDNF/ TrkB-TK+ signaling pathway, an important pathway for neuronal viability and function [48-57].

ALA treatment can be beneficial for the treatment of many neurological diseases, particularly stroke, which is the third leading cause of death worldwide $[58,59]$. Our findings were in accordance with the previous studies, confirming that ALA increases the expression of BDNF. Considering the neuroprotective and neurotrophic characteristics of BDNF, ALA treatment could be a feasible approach to reduce infarct size in stroke patients. Thus, ALA could be used in adjunction with routine stroke treatments to minimize lesions caused by stroke. Further research could attempt to replicate the present findings with a larger sample size. Furthermore, studying the molecular mechanisms underlying the positive effects of ALA on the nervous system might also be helpful. Future research can investigate the effects of ALA intake on stroke patients.

\section{Abbreviations}

ALA: a-Linolenic Acid; BDNF: Braine-derived Neurotrophic Factor; DHA: Docosahexaenoic acid; MDA: Malondialdehyde.

\section{Competing interests}

The authors declare that they have no competing interests. 


\section{Authors' contribution}

$\mathrm{MH}$ and MT conceived and designed the experiments. NS, AB, NM, MM, and MTJ performed the experiments and contributed to reagents/materials/ analysis tools. GYM and MH analyzed the data. BK, FA, and MT wrote the manuscript; contributed to the discussion S72-91and reviewed the manuscript. All authors read and approved the final manuscript.

\section{Acknowledgements}

This research was funded by a grant from the Cellular and Molecular Research Center at the Iran University of Medical Sciences (No. 12507).

\section{Author details}

${ }^{1}$ Cellular and Molecular Research Center, Iran University of Medical Sciences, Tehran, Iran. ${ }^{2}$ Department of Pharmacy, Faculty of Medicine, University of Malaya (UM), Kuala Lumpur, Malaysia. ${ }^{3}$ Faculty of Medicine, Iran University of Medical Sciences, Tehran, Iran. ${ }^{4}$ Department of Neurology, Faculty of Medicine, Iran University of Medical Sciences, Tehran, Iran. ${ }^{5}$ Brain and Spinal Cord Research Center, School of Advanced Medical Technologies, Tehran University of Medical Sciences, Tehran, Iran. 'Department of Anatomy, Faculty of Medicine, Iran University of Medical Sciences, Tehran, Iran. ${ }^{7}$ Department of Biochemistry and Molecular \& Cellular Biology, Georgetown University, Washington, USA. ${ }^{8}$ Department of Animal Science, Faculty of Veterinary Medicine, Universiti Putra Malaysia, Serdang, Malaysia.

Received: 6 November 2014 Accepted: 16 February 2015 Published online: 26 February 2015

\section{References}

1. Giusto NM, Salvador GA, Castagnet PI, Pasquare SJ, llincheta de Boschero MG. Age-associated changes in central nervous system glycerolipid composition and metabolism. Neurochem Res. 2002;27:1513-23.

2. Martinez M. Tissue levels of polyunsaturated fatty acids during early human development. J Pediatr. 1992;120:S129-38.

3. Rotstein NP, llincheta de Boschero MG, Giusto NM, Aveldano Ml. Effects of aging on the composition and metabolism of docosahexaenoatecontaining lipids of retina. Lipids. 1987:22:253-60.

4. Soderberg M, Edlund C, Kristensson K, Dallner G. Lipid compositions of different regions of the human brain during aging. J Neurochem. 1990;54:415-23.

5. Svennerholm L. Distribution and fatty acid composition of phosphoglycerides in normal human brain. J Lipid Res. 1968;9:570-9.

6. Innis SM. Essential fatty acids in growth and development. Prog Lipid Res. 1991;30:39-103.

7. Innis SM. Essential fatty acid metabolism during early development. In: Biology of Metabolism in Growing Animals. B.V. Amsterdam: Elsevier Science; 2005.

8. Bouwstra H, Dijck-Brouwer DA, Wildeman JA, Tjoonk HM, van der Heide JC, Boersma ER, et al. Long-chain polyunsaturated fatty acids have a positive effect on the quality of general movements of healthy term infants. Am J Clin Nutr. 2003;78:313-8.

9. Dullemeijer C, Durga J, Brouwer IA, van de Rest O, Kok FJ, Brummer RJ, et al $\mathrm{n} 3$ fatty acid proportions in plasma and cognitive performance in older adults. Am J Clin Nutr. 2007:86:1479-85.

10. Dunstan JA, Simmer K, Dixon G, Prescott SL. Cognitive assessment of children at age 2(1/2) years after maternal fish oil supplementation in pregnancy: a randomised controlled trial. Arch Dis Child Fetal Neonatal Ed. 2008;93:F45-50.

11. Helland IB, Smith L, Saarem K, Saugstad OD, Drevon CA. Maternal supplementation with very-long-chain n-3 fatty acids during pregnancy and lactation augments children's IQ at 4 years of age. Pediatrics. 2003;111:e39-44.

12. Hibbeln JR, Davis JM, Steer C, Emmett P, Rogers I, Williams C, et al. Maternal seafood consumption in pregnancy and neurodevelopmental outcomes in childhood (ALSPAC study): an observational cohort study. Lancet. 2007:369:578-85.

13. Innis SM, Friesen RW. Essential n-3 fatty acids in pregnant women and early visual acuity maturation in term infants. Am J Clin Nutr. 2008:87:548-57.

14. Innis SM, Gilley J, Werker J. Are human milk long-chain polyunsaturated fatty acids related to visual and neural development in breast-fed term infants? J Pediatr. 2001;139:532-8.
15. Kalmijn S, van Boxtel MP, Ocke M, Verschuren WM, Kromhout D, Launer LJ. Dietary intake of fatty acids and fish in relation to cognitive performance at middle age. Neurology. 2004;62:275-80.

16. Morris MC, Evans DA, Bienias JL, Tangney CC, Bennett DA, Wilson RS, et al Consumption of fish and n-3 fatty acids and risk of incident Alzheimer disease. Arch Neurol. 2003:60:940-6.

17. Nurk E, Drevon CA, Refsum H, Solvoll K, Vollset SE, Nygard O, et al. Cognitive performance among the elderly and dietary fish intake: the Hordaland Health Study. Am J Clin Nutr. 2007:86:1470-8.

18. Oken E, Wright RO, Kleinman KP, Bellinger D, Amarasiriwardena CJ, Hu H, et al. Maternal fish consumption, hair mercury, and infant cognition in a U.S. Cohort. Environ Health Perspect. 2005;113:1376-80.

19. Schaeffer L, Gohlke H, Muller M, Heid IM, Palmer $\sqcup$, Kompauer I, et al. Common genetic variants of the FADS1 FADS2 gene cluster and their reconstructed haplotypes are associated with the fatty acid composition in phospholipids. Hum Mol Genet. 2006;15:1745-56.

20. Uauy R, Dangour AD. Nutrition in brain development and aging: role of essential fatty acids. Nutr Rev. 2006;64:S24-33. discussion S72-91.

21. van Gelder BM, Tijhuis M, Kalmijn S, Kromhout D. Fish consumption, n-3 fatty acids, and subsequent 5-y cognitive decline in elderly men: the Zutphen Elderly Study. Am J Clin Nutr. 2007;85:1142-7.

22. Williams C, Birch EE, Emmett PM, Northstone K. Avon Longitudinal Study of P, Childhood Study T. Stereoacuity at age $3.5 \mathrm{y}$ in children born full-term is associated with prenatal and postnatal dietary factors: a report from a population-based cohort study. Am J Clin Nutr. 2001;73:316-22.

23. Beltz BS, Tlusty MF, Benton JL, Sandeman DC. Omega-3 fatty acids upregulate adult neurogenesis. Neurosci Lett. 2007:415:154-8.

24. Wu A, Ying Z, Gomez-Pinilla F. Dietary omega-3 fatty acids normalize BDNF levels, reduce oxidative damage, and counteract learning disability after traumatic brain injury in rats. J Neurotrauma. 2004;21:1457-67.

25. Loeliger MM, Briscoe T, Rees SM. BDNF increases survival of retinal dopaminergic neurons after prenatal compromise. Invest Ophthalmol Vis Sci. 2008;49:1282-9.

26. Mattson MP, Maudsley S, Martin B. A neural signaling triumvirate that influences ageing and age-related disease: insulin/IGF-1, BDNF and serotonin. Ageing Res Rev. 2004:3:445-64.

27. Blondeau N, Widmann C, Lazdunski M, Heurteaux C. Polyunsaturated fatty acids induce ischemic and epileptic tolerance. Neuroscience. 2002;109:231-41.

28. Heurteaux C, Guy N, Laigle C, Blondeau N, Duprat F, Mazzuca M, et al. TREK-1, a $\mathrm{K}+$ channel involved in neuroprotection and general anesthesia. EMBO J. 2004;23:2684-95

29. Huang WL, King VR, Curran OE, Dyall SC, Ward RE, Lal N, et al. A combination of intravenous and dietary docosahexaenoic acid significantly improves outcome after spinal cord injury. Brain. 2007;130:3004-19.

30. King VR, Huang WL, Dyall SC, Curran OE, Priestley JV, Michael-Titus AT. Omega-3 fatty acids improve recovery, whereas omega-6 fatty acids worsen outcome, after spinal cord injury in the adult rat. J Neurosci. 2006:26:4672-80.

31. Lang-Lazdunski L, Blondeau N, Jarretou G, Lazdunski M, Heurteaux C. Linolenic acid prevents neuronal cell death and paraplegia after transient spinal cord ischemia in rats. J Vasc Surg. 2003;38:564-75.

32. Lauritzen I, Blondeau N, Heurteaux C, Widmann C, Romey G, Lazdunski M. Polyunsaturated fatty acids are potent neuroprotectors. EMBO J. 2000:19:1784-93.

33. Blondeau N, Petrault O, Manta S, Giordanengo V, Gounon P, Bordet R, et al Polyunsaturated fatty acids are cerebral vasodilators via the TREK-1 potassium channel. Circ Res. 2007;101:176-84

34. Blondeau N, Widmann C, Lazdunski M, Heurteaux C. Activation of the nuclear factor-kappaB is a key event in brain tolerance. J Neurosci. 2001;21:4668-77.

35. Heurteaux C, Laigle C, Blondeau N, Jarretou G, Lazdunski M. Alpha-linolenic acid and riluzole treatment confer cerebral protection and improve survival after focal brain ischemia. Neuroscience. 2006;137:241-51.

36. Xiao YF, Wright SN, Wang GK, Morgan JP, Leaf A. Fatty acids suppress voltagegated $\mathrm{Na}+$ currents in HEK293t cells transfected with the alpha-subunit of the human cardiac Na + channel. Proc Natl Acad Sci U S A. 1998;95:2680-5.

37. Blondeau N, Nguemeni C, Debruyne DN, Piens M, Wu X, Pan H, et al. Subchronic alpha-linolenic acid treatment enhances brain plasticity and exerts an antidepressant effect: a versatile potential therapy for stroke. Neuropsychopharmacology. 2009;34:2548-59.

38. Nguemeni C, Delplanque B, Rovere C, Simon-Rousseau N, Gandin C, Agnani $\mathrm{G}$, et al. Dietary supplementation of alpha-linolenic acid in an enriched rapeseed oil diet protects from stroke. Pharmacol Res. 2010;61:226-33. 
39. Schindowski K, Belarbi K, Buee L. Neurotrophic factors in Alzheimer's disease: role of axonal transport. Genes Brain Behav. 2008;7 Suppl 1:43-56.

40. Patapoutian A, Reichardt LF. Trk receptors: mediators of neurotrophin action. Curr Opin Neurobiol. 2001;11:272-80.

41. Bartkowska K, Turlejski K, Djavadian RL. Neurotrophins and their receptors in early development of the mammalian nervous system. Acta Neurobiol Exp. 2010;70:454-67.

42. Bath KG, Mandairon N, Jing D, Rajagopal R, Kapoor R, Chen ZY, et al. Variant brain-derived neurotrophic factor (Val66Met) alters adult olfactory bulb neurogenesis and spontaneous olfactory discrimination. J Neurosci. 2008;28:2383-93.

43. Kirschenbaum B, Goldman SA. Brain-derived neurotrophic factor promotes the survival of neurons arising from the adult rat forebrain subependymal zone. Proc Natl Acad Sci U S A. 1995;92:210-4.

44. Bergami M, Rimondini R, Santi S, Blum R, Gotz M, Canossa M. Deletion of TrkB in adult progenitors alters newborn neuron integration into hippocampal circuits and increases anxiety-like behavior. Proc Natl Acad Sci U S A. 2008;105:15570-5.

45. Mattson MP. Glutamate and neurotrophic factors in neuronal plasticity and disease. Ann N Y Acad Sci. 2008;1144:97-112.

46. Nagahara $\mathrm{AH}$, Tuszynski MH. Potential therapeutic uses of BDNF in neurological and psychiatric disorders. Nat Rev Drug Discov. 2011;10:209-19.

47. Pazyra-Murphy MF, Hans A, Courchesne SL, Karch C, Cosker KE, Heerssen $\mathrm{HM}$, et al. A retrograde neuronal survival response: target-derived neurotrophins regulate MEF2D and bcl-w. J Neurosci. 2009;29:6700-9.

48. Allen SJ, Wilcock GK, Dawbarn D. Profound and selective loss of catalytic TrkB immunoreactivity in Alzheimer's disease. Biochem Biophys Res Commun. 1999:264:648-51.

49. Connor B, Young D, Yan Q, Faull RL, Synek B, Dragunow M. Brain-derived neurotrophic factor is reduced in Alzheimer's disease. Brain Res Mol Brain Res. 1997:49:71-81.

50. Fahnestock M, Garzon D, Holsinger RM, Michalski B. Neurotrophic factors and Alzheimer's disease: are we focusing on the wrong molecule? J Neura Transm Suppl. 2002;62:241-52.

51. Ferrer I, Marin C, Rey MJ, Ribalta T, Goutan E, Blanco R, et al. BDNF and full-length and truncated TrkB expression in Alzheimer disease. Implications in therapeutic strategies. J Neuropathol Exp Neurol. 1999:58:729-39.

52. Garzon D, Yu G, Fahnestock M. A new brain-derived neurotrophic factor transcript and decrease in brain-derived neurotrophic factor transcripts 1,2 and 3 in Alzheimer's disease parietal cortex. J Neurochem. 2002;82:1058-64.

53. Hock C, Heese K, Hulette C, Rosenberg C, Otten U. Region-specific neurotrophin imbalances in Alzheimer disease: decreased levels of brain-derived neurotrophic factor and increased levels of nerve growth factor in hippocampus and cortical areas. Arch Neurol. 2000:57:846-51.

54. Holsinger RM, Schnarr J, Henry P, Castelo VT, Fahnestock M. Quantitation of BDNF mRNA in human parietal cortex by competitive reverse transcriptionpolymerase chain reaction: decreased levels in Alzheimer's disease. Brain Res Mol Brain Res. 2000;76:347-54

55. Michalski B, Fahnestock M. Pro-brain-derived neurotrophic factor is decreased in parietal cortex in Alzheimer's disease. Brain Res Mol Brain Res, 2003;111:148-54

56. Peng S, Wuu J, Mufson EJ, Fahnestock M. Precursor form of brain-derived neurotrophic factor and mature brain-derived neurotrophic factor are decreased in the pre-clinical stages of Alzheimer's disease. J Neurochem. 2005:93:1412-21.

57. Phillips HS, Hains JM, Armanini M, Laramee GR, Johnson SA, Winslow JW BDNF mRNA is decreased in the hippocampus of individuals with Alzheimer's disease. Neuron. 1991;7:695-702.

58. Lloyd-Jones D, Adams RJ, Brown TM, Carnethon M, Dai S, De Simone G, et al. Executive summary: heart disease and stroke statistics-2010 update: a report from the American Heart Association. Circulation. 2010;121:948-54.

59. Rosamond W, Flegal K, Furie K, Go A, Greenlund K, Haase N, et al. Heart disease and stroke statistics-2008 update: a report from the American Heart Association Statistics Committee and Stroke Statistics Subcommittee. Circulation. 2008;117:e25-146.

\section{Submit your next manuscript to BioMed Central and take full advantage of:}

- Convenient online submission

- Thorough peer review

- No space constraints or color figure charges

- Immediate publication on acceptance

- Inclusion in PubMed, CAS, Scopus and Google Scholar

- Research which is freely available for redistribution 